\title{
Development and blood compatibility assessment of electrospun polyvinyl alcohol blended with metallocene polyethylene and plectranthus amboinicus (PVA/mPE/PA) for bone tissue engineering
}

This article was published in the following Dove Press journal: International Journal of Nanomedicine

\author{
Jie $Q i^{1, *}$ \\ Huang Zhang ${ }^{2, *}$ \\ Yingzhou Wang ${ }^{3}$ \\ Mohan Prasath Mani ${ }^{4}$ \\ Saravana Kumar \\ Jaganathan ${ }^{5-7}$ \\ 'Department of Orthopedics, \\ Shaanxi Provincial People's Hospital, \\ ${ }^{2}$ Department of Orthopedics, \\ Han Zhong People's Hospital, Han \\ Zhong, Shaanxi Province, ${ }^{3}$ Beijing \\ Meinuoyikang Health Food Co., Ltd, \\ Beijing, People's Republic of China; \\ ${ }^{4}$ Faculty of Biosciences and Medical \\ Engineering, Universiti Teknologi \\ Malaysia, Skudai, Johor, Malaysia; \\ ${ }^{5}$ Department for Management of \\ Science and Technology Development, \\ ${ }^{6}$ Faculty of Applied Sciences, Ton Duc \\ Thang University, Ho Chi Minh City, \\ Vietnam; ${ }^{7}$ IJN-UTM Cardiovascular \\ Engineering Centre, Department \\ of Clinical Sciences, Faculty of \\ Biosciences and Medical Engineering, \\ Universiti Teknologi Malaysia, Skudai, \\ Johor, Malaysia \\ *These authors contributed equally \\ to this work
}

Correspondence: Saravana Kumar Jaganathan

Department for Management of Science and Technology Development,

Ton Duc Thang University, Ho Chi

Minh City, Vietnam

Tel +84837755037

Email saravana@tdt.edu.vn
Introduction: Currently, the design of extracellular matrix (ECM) with nanoscale properties in bone tissue engineering is challenging. For bone tissue engineering, the ECM must have certain properties such as being nontoxic, highly porous, and should not cause foreign body reactions. Materials and methods: In this study, the hybrid scaffold based on polyvinyl alcohol (PVA) blended with metallocene polyethylene ( $\mathrm{mPE}$ ) and plectranthus amboinicus (PA) was fabricated for bone tissue engineering via electrospinning. The fabricated hybrid nanocomposites were characterized by scanning electron microscopy (SEM), Fourier transform and infrared spectroscopy (FTIR), thermogravimetric analysis (TGA), contact angle measurement, and atomic force microscopy (AFM). Furthermore, activated partial thromboplastin time (APTT), prothrombin time (PT), and hemolytic assays were used to investigate the blood compatibility of the prepared hybrid nanocomposites. Results: The prepared hybrid nanocomposites showed reduced fiber diameter $(238 \pm 45 \mathrm{~nm})$ and also increased porosity (87\%) with decreased pore diameter $(340 \pm 86 \mathrm{~nm})$ compared with pure PVA. The interactions between PVA, mPE, and PA were identified by the formation of the additional peaks as revealed in FTIR. Furthermore, the prepared hybrid nanocomposites showed a decreased contact angle of $51^{\circ} \pm 1.32^{\circ}$ indicating a hydrophilic nature and exhibited lower thermal stability compared to pristine PVA. Moreover, the mechanical results revealed that the electrospun scaffold showed an improved tensile strength of $3.55 \pm 0.29 \mathrm{MPa}$ compared with the pristine PVA $(1.8 \pm 0.52 \mathrm{MPa})$. The prepared hybrid nanocomposites showed delayed blood clotting as noted in APTT and PT assays indicating better blood compatibility. Moreover, the hemolysis assay revealed that the hybrid nanocomposites exhibited a low hemolytic index of $0.6 \%$ compared with pure PVA, which was $1.6 \%$ suggesting the safety of the developed nanocomposite to red blood cells (RBCs). Conclusion: The prepared nanocomposites exhibited better physico-chemical properties, sufficient porosity, mechanical strength, and blood compatibility, which favors it as a valuable candidate in bone tissue engineering for repairing the bone defects.

Keywords: scaffold, electrospinning, bone tissue engineering, physico-chemical characterization, blood compatibility

\section{Introduction}

Finding clinical applications for the repair of massive bone defects produced by disease or trauma is a challenge. The diseases or traumas included in this list are tumor ablation, bone cysts, osteolysis, and neurosurgical defects. ${ }^{1}$ Recently, in biomedical 
applications, bone tissue engineering is promising as a new approach for bone repair. The tissue-engineered bone scaffold helps in eliminating problems of donor scarcity, supply limitation, pathogen transfer, and immune rejection compared to traditional autograft and allograft procedures. ${ }^{2}$ Moreover, tissue-engineered bone possesses an extracellular matrix (ECM), which helps in promoting osteoblast proliferation for the differentiation, growth, and mineralized tissue formation. ${ }^{3,4}$ The ideal scaffold in bone tissue engineering must be biocompatible, biodegradable, nontoxic, and highly porous and should not cause foreign body reactions. Furthermore, it should have significant mechanical and physical properties in order to meet the need of bone tissue engineering. ${ }^{5,6}$ Currently, a variety of materials are utilized in repairing the damaged or traumatized bone tissue. The materials include metals, ceramics, and polymers (natural and synthetic). ${ }^{7}$ Owing to many disadvantages in metals and ceramics, such as lack of degradability in a biological environment and limited process ability, their utilization in bone tissue-engineering applications is restricted. ${ }^{8}$ In contrast, polymers are attractive due to design flexibility and may be easily tailored according to the specific needs. ${ }^{9}$ The commonly used polymers in bone tissue engineering are poly(lactic acid), poly(glycolic acid), poly(lactic-co-glycolic acid) (PLGA), poly(caprolactone), and natural polymers such as collagen, gelatin, silk, and chitosan. ${ }^{10}$

The design of scaffolds as ECM in guiding the tissue regeneration process is still challenging in bone tissue engineering. For tissue-engineering applications, the fabricated scaffolds should imitate the biological functions and also resemble the structure of the ECM. ${ }^{4,11,12}$ Moreover, the developed scaffolds should provide sufficient mechanical support to direct the inductive molecules or cells to the repair site for the generation of new tissue growth. There are many techniques such as particle leaching, phase separation, and self-assembly to develop three-dimensional porous architectures..$^{3,4}$ However, the scaffolds developed using these techniques do not effectively imitate the structure of the natural ECM, which limits the bone tissue formation. ${ }^{4}$ ECM is a natural composite in which the fibrous collagens are embedded in a three-dimensional porous network. The hierarchical 3D porous structure was made of collagen fibers with tissue architecture that ranges from nanometer to macroscopic dimensions. ${ }^{13}$ The scaffold generated by an electrospinning technique has nanoscale fibers that resemble the topographic features of the ECM. Nowadays, the electrospun fibrous scaffold has been widely used for tissue engineering. Moreover, many studies have focused on processing the various natural and synthetic polymers in fabricating porous scaffold for tissue-engineering applications. ${ }^{11,14-16}$

Electrospinning is a versatile and cost-effective technique that produces fibers in nanoscale diameters with the aid of a high electric field. In the electrospinning setup, the polymer solution in a syringe needle is subjected to an electric field and the polymer jet is converted into nanofibers when the electric field overcomes the threshold voltage. The resulting nanofibers are deposited in the form of a nonwoven fabric on the collector drum. Electrospinning is a versatile technique for fabricating the scaffold for tissue-engineered applications because control of fiber diameters and porosity may be performed by adjusting solution properties and operating parameters. ${ }^{17-19}$ In this study, the polymer used in fabricating the scaffold was polyvinyl alcohol (PVA). The various applications of PVA composites in biomedical applications include manufacturing of contact lenses, artificial heart surgery, drug delivery systems, and wound dressings. ${ }^{20}$ Furthermore, PVA is used as a biomaterial in medical devices because of its favorable properties such as biocompatibility, nontoxicity, noncarcinogenicity, swelling properties, and bioadhesive characteristics. ${ }^{21}$

Another material used in this study was metallocene polyethylene (mPE). The metallocene-based polyolefins possess enhanced toughness, seal ability, clarity, and elasticity. ${ }^{22} \mathrm{mPE}$ provides excellent permeability to oxygen and also acts as a barrier toward ammonia and water. Currently, mPE is used in many medical applications such as disposable bags, storage bottles, blood bags, and syringe tubes. ${ }^{23}$ Generally, the use of PVA in certain applications is limited by low strength ${ }^{20}$ and it is hypothesized that adding mPE will provide suitable strength to the electrospun membrane. Furthermore, leaves of plectranthus amboinicus (PA) were blended with the composite to improve its properties. The leaves of PA have been used as flavoring agents in meat and poultry, as ornamentals, and also as essential oils. PA leaves were also utilized for other ranges of problems such as infections, rheumatism, and flatulence. ${ }^{24,25}$ The constituents of PA were reported to have various bioactivities such as antioxidant, antibacterial, antimicrobial, antifungal, and wound healing activities. Moreover, the constituents of PA were found to possess anti-inflammatory activity inhibiting the activator protein-1 (AP-1) and tumor necrosis factor (TNF- $\alpha$ ), which are vital for the pathogenesis of inflammatory bone resorption. ${ }^{26}$ In this study, a novel bionanocomposite based on PVA blended with $\mathrm{MPE}$ and PA will be fabricated using a single-step electrospinning process. The aim of this study was the fabrication and investigation of physico-chemical 
characterization and mechanical properties of the developed nanocomposite. Furthermore, blood compatibility assays were performed to assess the safety of the fabricated nanocomposite along with the pure PVA nanofibers.

\section{Materials and methods Materials}

The following materials were used in this study: PVA was from Sigma-Aldrich Co. (St Louis, MO, USA); mPE sheets were gifts from Indian Institute of Technology (Kharagpur, India); fresh leaves of PA were obtained locally; phosphatebuffered saline (PBS) and physiological saline $(0.9 \%, \mathrm{w} / \mathrm{v})$ were from Sigma-Aldrich Co.; and the coagulation assay reagents were from Diagnostic Enterprises (Solan, India).

\section{Preparation of nanocomposite}

Distilled water was used as a solvent for PVA, and $10 \mathrm{wt} \%$ of PVA was used for the preparation of the nanocomposite. To prepare $10 \mathrm{wt} \%$ of PVA, $0.70 \mathrm{~g}$ of PVA polymer was mixed in $7 \mathrm{~mL}$ of distilled water and stirred for $12 \mathrm{~h}$ at room temperature to obtain a clear homogeneous solution. Both $\mathrm{mPE}$ and PA were incorporated into the PVA matrix at a concentration of $1 \mathrm{wt} \%$. To prepare $1 \mathrm{wt} \%$ of $\mathrm{mPE}, 0.030 \mathrm{~g}$ of $\mathrm{mPE}$ was mixed in $3 \mathrm{~mL}$ of xylene and stirred for $24 \mathrm{~h}$ until the homogeneous solution was obtained. Similarly, the homogeneous solution of PA was obtained by adding $30 \mu \mathrm{L}$ of PA in $3 \mathrm{~mL}$ of distilled water and stirred for $3 \mathrm{~h}$ at room temperature. Finally, the PVA/mPE/PA nanocomposite was obtained by adding the prepared homogeneous solution of mPE and PA solutions in PVA at the ratio of $8: 1: 1(\mathrm{v} / \mathrm{v})$ and stirred for $2 \mathrm{~h}$ for the uniform dispersion.

\section{Fabrication of PVA and nanocomposite dressing}

The pure PVA nanofiber and PVA/mPE/PA nanocomposites were obtained by an electrospinning technique. Electrospinning of both PVA and PVA/mPE/PA nanofibers was performed at an applied voltage of $10 \mathrm{kV}$ with a flow rate of $0.5 \mathrm{~mL} / \mathrm{h}$. The obtained nanofibers were deposited on the collector, which was placed at $17 \mathrm{~cm}$ from the tip of the needle. The fabricated PVA and PVA/mPE/PA scaffolds were dried at room temperature under vacuum.

\section{Physico-chemical characterizations}

\section{Scanning electron microscopy (SEM) micrographs}

The electrospun PVA and PVA/mPE/PA nanocomposites were investigated using the Tabletop TM-300 (Hitachi Ltd., Tokyo, Japan) to analyze the morphological features.
Before obtaining microphotographs, the fabricated membranes were coated with gold and the average fiber diameter was calculated using the ImageJ software (Bethesda, MD, USA).

Attenuated total reflectance Fourier transform infrared spectroscopy (ATR-FTIR) analysis

The spectra of electrospun PVA and PVA/mPE/PA were obtained using the Nicolet iS5 ATR-FTIR unit (Thermo Fischer Scientific, Waltham, MA, USA). Initially, the samples of electrospun PVA and PVA/mPE/PA were placed on the sensor and scanned at a resolution of $4 / \mathrm{cm}$ in the frequency range of $600-4,000 \mathrm{~cm}^{-1}$ to examine the presence of characteristic peaks.

\section{Porosity and pore size measurement}

The density bottle method was used to measure the porosity percentage of the pure PVA and the prepared PVA/mPE/PA. Then, the apparent density $\left(\rho_{i}\right)$ was calculated using the following formula:

$$
\begin{aligned}
& \text { Apparent density }\left(\rho_{i}\right) \\
& =\frac{\text { Weight of the nanofiber membrane }(\mathrm{m})}{\text { Thickness }(\mathrm{t}) \times \text { Area of the sample }(1 \times \mathrm{w})}
\end{aligned}
$$

After calculating the apparent density $\left(\rho_{i}\right)$ and the bulk/ standard density $\rho_{0}$ of PVA, the values were placed in the following equation to calculate the porosity percentage $(\varepsilon)$ :

$$
\text { Porosity percentage }(\varepsilon)=\left(1-\frac{\rho}{\rho_{0}}\right) \times 100 \%
$$

Finally, the average pore size diameter in both PVA and $\mathrm{PVA} / \mathrm{mPE} / \mathrm{PA}$ was calculated using Image J and the obtained values were explored into the Excel sheet to draw the pore size distribution.

\section{Contact angle measurements}

The wettability of electrospun PVA and PVA/mPE/PA was calculated using the VCA Optima (AST Products, Inc., Billerica, MA, USA) contact angle measurement unit. The measurement was performed by placing a water drop on the sample, and the image of the water droplet on the membranes was captured using high-resolution camera. From the captured image, the mean contact angles were calculated using the computer-integrated software.

\section{Thermogravimetric analysis (TGA)}

The thermal properties of electrospun PVA and PVA/mPE/ PA were investigated using the TGA unit (PerkinElmer 
Inc., Waltham, MA, USA). The thermal properties were determined by heating a sample weighing $3 \mathrm{mg}$ from 50 to $1,000^{\circ} \mathrm{C}$ at $10^{\circ} \mathrm{C} / \mathrm{min}$.

\section{Mechanical testing}

The mechanical testing was measured according to ASTM D638-98 standard using a uniaxial load test machine (AI-3000; Gotech Testing Machines, Taichung, Taiwan). To begin, a small piece of electrospun PVA and PVA/mPE/PA was mounted on its cut ends and the testing was carried out at a cross-head speed of $5 \mathrm{~mm} / \mathrm{min}$ until the onset failure occurs. Then, the tensile strength and Young's modulus (modulus of elasticity) were calculated from the slope of the stress-strain curve.

\section{Functionalization of PVA and PVA/mPE/PA nanocomposites}

Functionalization was performed through a heating method. Samples with a size of $2 \times 2 \mathrm{~cm}^{2}$ were cut and placed on the heating unit. Heating was performed at $70^{\circ} \mathrm{C}$ for 7 days in room temperature continuously. ${ }^{27}$ After heating, the samples were weighed $\left(W_{\mathrm{d}}\right)$ and then immersed into warm distilled water $\left(37.0^{\circ} \mathrm{C}\right)$ for 1,7 , and 14 days. $^{28}$ After 1,7 , and 14 days, the samples were taken out and the weight of the immersed samples (Wi) was measured after drying. Finally, the solubility in water for both samples was calculated.

\section{Blood compatibility assessments}

\section{Ethical approval and blood sample procurement}

The coagulation assay procedures were approved by the Chairman, Ethical and Medical Researcher Committee, Universiti Tekonologi Malaysia, with the ref no UTM.J.45.01/ 25.10/3Jld.2(3). Before the procedures, a written consent form was given to the healthy volunteers. They were informed about the risks and benefits and they signed the informed consent before blood withdrawal. The blood collection and the preparation of platelet-poor plasma (PPP) were carried out as reported in previous work. ${ }^{29}$

\section{Activated partial thromboplastin time (APTT)}

The APTT assay was used to measure the activation of intrinsic pathway to detect the blood compatibility of pure PVA nanofiber and PVA/mPE/PA nanocomposite. To begin, the samples of PVA nanofiber and PVA/mPE/PA nanocomposite were added to $100 \mu \mathrm{L}$ of PPP and incubated at $37^{\circ} \mathrm{C}$. Then, the mixture was added with $100 \mu \mathrm{L}$ of rabbit brain cephalin followed by adding $50 \mu \mathrm{L}$ of $\mathrm{CaCl}_{2}$. Finally, the mixture was stirred using a needle and time taken for the appearance of the initial clot was measured using a chronometer. ${ }^{29}$
Prothrombin time (PT)

PT was calculated for pure PVA nanofiber and PVA/mPE/PA nanocomposite to investigate the activation of the extrinsic pathway. For the PT assay, cut samples of fabricated pure PVA nanofiber and $\mathrm{PVA} / \mathrm{mPE} / \mathrm{PA}$ nanocomposite $\left(0.5 \times 0.5 \mathrm{~cm}^{2}\right)$ were added with $100 \mu \mathrm{L}$ of PPP and incubated at $37^{\circ} \mathrm{C}$. Then, the mixture was activated by adding $0.9 \%$ of $\mathrm{NaCl}$-thromboplastin (Factor III, $100 \mathrm{~mL}$ )-containing $\mathrm{Ca}^{2+}$ ions and the initiation for clot formation was identified using a chronometer. ${ }^{29}$

\section{Hemolysis assay}

To begin this assay, the fabricated pure PVA nanofiber and $\mathrm{PVA} / \mathrm{mPE} / \mathrm{PA}$ were cut into small pieces with the dimension of $1 \times 1 \mathrm{~cm}$ and equilibrated in $4 \mathrm{~mL}$ of saline for $30 \mathrm{~min}$ at $37^{\circ} \mathrm{C}$. After that, the samples were exposed to $0.2 \mathrm{~mL}$ of diluted blood and incubated for $60 \mathrm{~min}$ at $37^{\circ} \mathrm{C}$. The positive and negative controls were constituted by mixing human blood into distilled water in the ratio 4:5 (100\% hemolysis) and the physiological saline solution, respectively. Then, the mixture was retrieved and centrifuged at 1,000 rpm for $5 \mathrm{~min}$. After that, the absorbance of the supernatant was measured at $545 \mathrm{~nm}$, which represents the damage of red blood cell (RBC). The percentage of hemolysis or hemolytic index was calculated using the protocol as described earlier. ${ }^{29}$

\section{Statistical analysis}

In this study, all the experiments were performed thrice independently. Using unpaired $t$-test, the statistical significance was determined and the results obtained were expressed in mean $\pm \mathrm{SD}$.

\section{Results and discussion Morphological analysis}

The SEM images denote the morphology of the electrospun PVA and PVA/mPE/PA nanocomposites. The SEM analysis clearly indicates that the electrospun PVA and PVA $/ \mathrm{mPE} /$ PA nanocomposites possessed beadless fibers as shown in Figure 1A and B. The fiber diameters of PVA and PVA/ $\mathrm{mPE} / \mathrm{PA}$ nanocomposites were found to be $326 \pm 56$ and $238 \pm 45 \mathrm{~nm}$, respectively. The obtained results clearly showed that the PVA/mPE/PA nanocomposites showed reduced fiber diameter compared to pure PVA. The corresponding fiber distribution curve for the electrospun PVA and PVA $/ \mathrm{mPE} /$ PA nanocomposites are shown in Figure 2A and B. Linh and Lee utilized PVA scaffold blended with gelatin for bone tissue engineering application. It was observed that the fiber diameter of electrospun PVA nanofibers was $250 \pm 20 \mathrm{~nm}$, whereas PVA/gelation showed reduced fiber diameter in the 


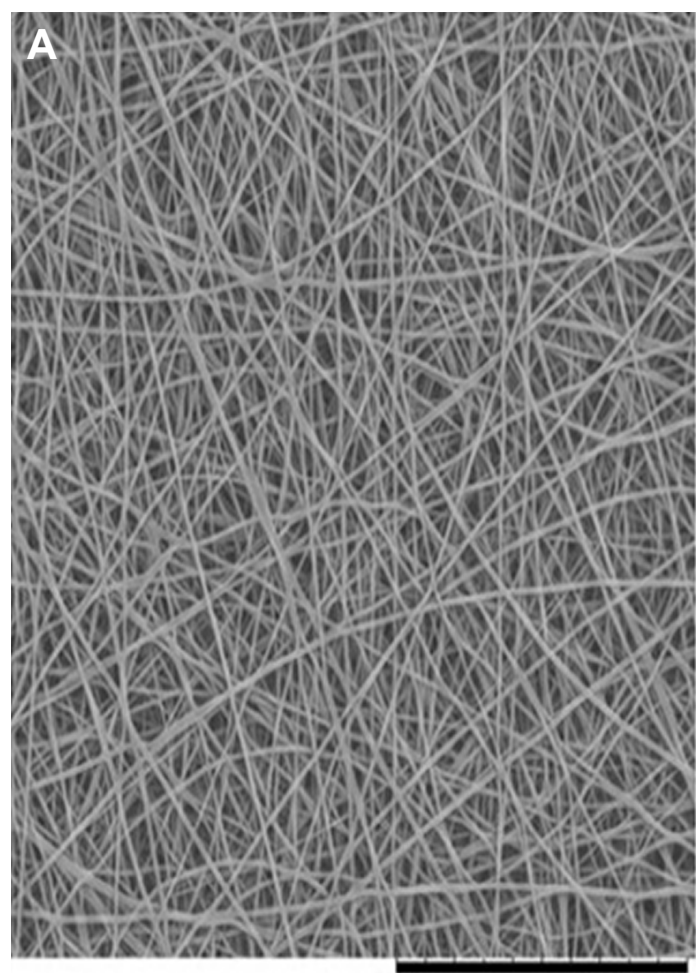

$09: 34 \mathrm{NL} \times 2.5 \mathrm{k} 30 \mu \mathrm{m}$

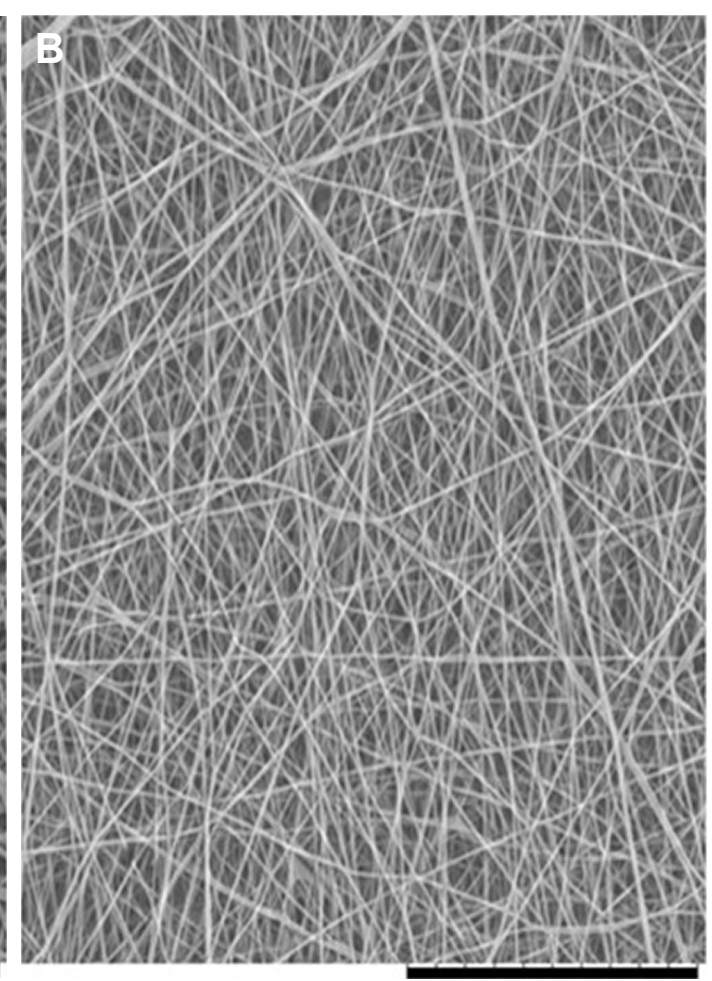

09:47 NL $\times 2.5 \mathrm{k} 30 \mu \mathrm{m}$

Figure I SEM images of (A) PVA membrane and (B) PVA/mPE/PA nanocomposites.

Abbreviations: mPE, metallocene polyethylene; PA, plectranthus amboinicus; PVA, polyvinyl alcohol; SEM, scanning electron microscopy.

range of $150 \pm 10 \mathrm{~nm}$. Furthermore, the PVA/gelatin scaffold with smaller fiber diameter showed enhanced osteoblast proliferation compared to pure PVA. ${ }^{30}$ In our study, the fiber diameter of electrospun PVA/mPE/PA nanocomposites was found to be of similar range, which seems to be conducive for enhanced bone tissue growth.

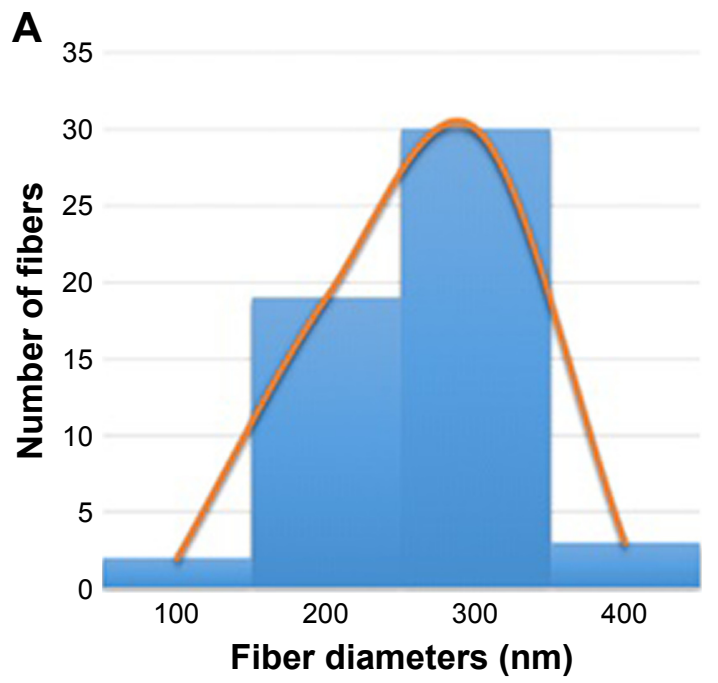

\section{ATR-FTIR analysis}

The characteristic peaks present in the PVA, mPE, PA, and $\mathrm{PVA} / \mathrm{mPE} / \mathrm{PA}$ are indicated in Figure 3 . In the absorption band of PVA, a broad band visible at $3,325 \mathrm{~cm}^{-1}$ signals the $\mathrm{OH}$ group. A sharp peak seen at 2,918 $\mathrm{cm}^{-1}$ denotes the $\mathrm{CH}$ stretching, and the peaks at 1,375 and $1,435 \mathrm{~cm}^{-1}$ indicate

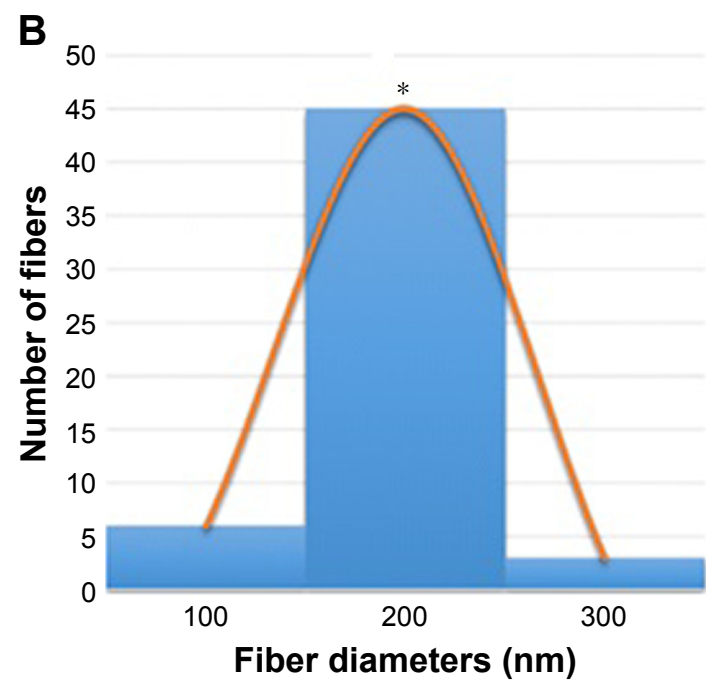

Figure 2 Fiber distribution curves of (A) PVA membrane and (B) PVA/mPE/PA nanocomposites.

Note: *Mean differences were significant compared with pure PVA $(P<0.05)$.

Abbreviations: $\mathrm{mPE}$, metallocene polyethylene; PA, plectranthus amboinicus; PVA, polyvinyl alcohol. 


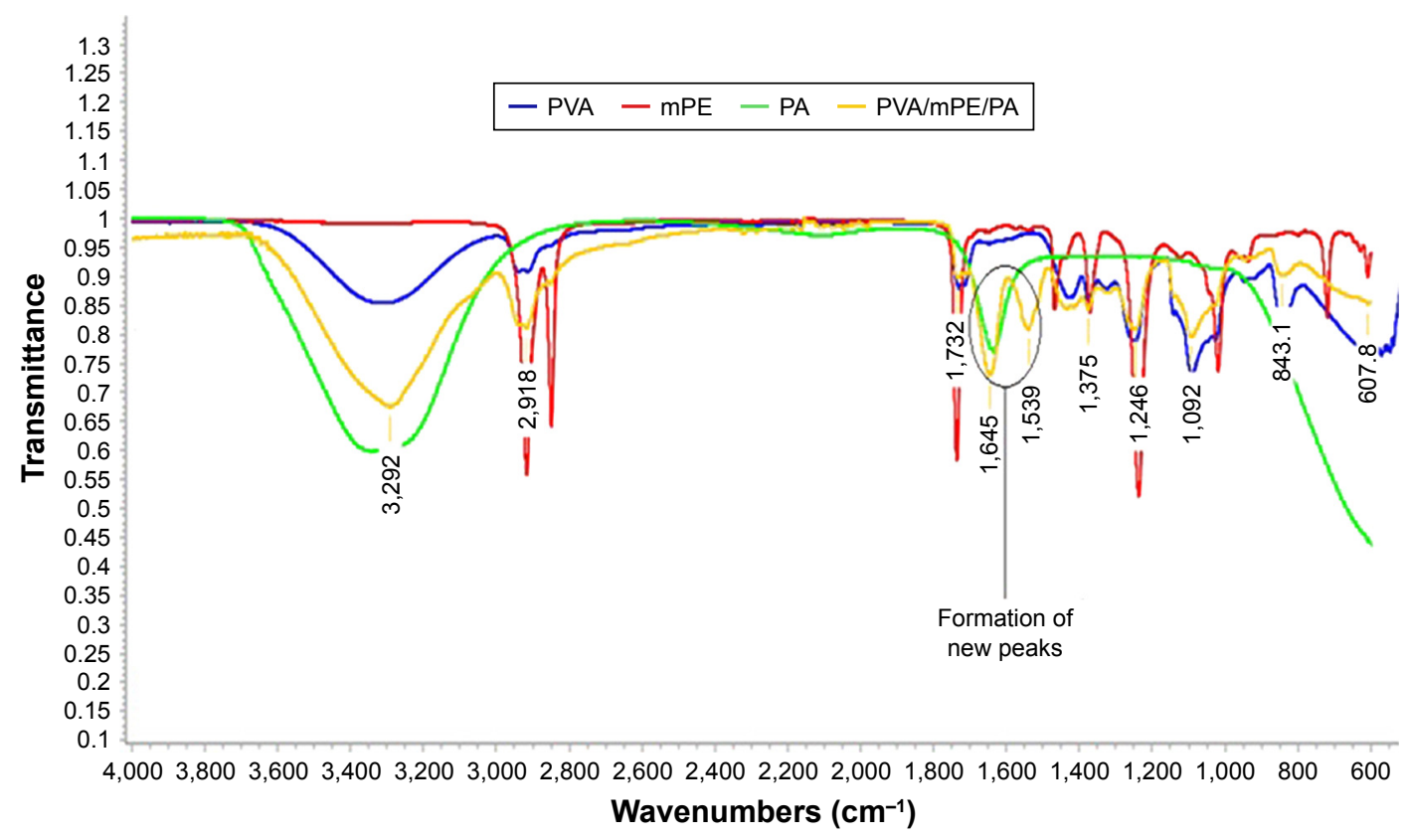

Figure 3 Infrared spectrum of PVA membrane, mPE, PA, and PVA/mPE/PA nanocomposites.

Abbreviations: $\mathrm{mPE}$, metallocene polyethylene; PA, plectranthus amboinicus; PVA, polyvinyl alcohol.

$\mathrm{CH}$ vibrations. The presence of carboxylic $(\mathrm{C}=\mathrm{O})$ stretching was observed at 1,732, and bands at 1,246, 1,092, 843, and $607 \mathrm{~cm}^{-1}$ indicate the $\mathrm{C}-\mathrm{O}$ stretching corresponding to alcohol groups. ${ }^{31,32}$ Similarly, in the $\mathrm{mPE}$ spectrum, a sharp twin peak at 2,917 and $2,849 \mathrm{~cm}^{-1}$ indicating the $\mathrm{CH}$ stretching and the vibrations of $\mathrm{CH}$ stretching was identified by the characteristic bands at 1,371 and $1,468 \mathrm{~cm}^{-1}$, respectively. Furthermore, a band seen at $1,737 \mathrm{~cm}^{-1}$ indicates the $\mathrm{C}-\mathrm{O}$ stretching and their vibrations of $\mathrm{C}-\mathrm{O}$ corresponding to alcohol were seen at $1,237,1,019$, and $719 \mathrm{~cm}^{-1}$, respectively. ${ }^{33}$ Similarly, in the IR spectrum of PA, a wide band observed at $3,345 \mathrm{~cm}^{-1}$ indicates the $\mathrm{OH}$ stretching and a sharp peak at $1,634 \mathrm{~cm}^{-1}$ indicates the $\mathrm{C}=\mathrm{O}$ stretching. From the IR spectrum of $\mathrm{PVA} / \mathrm{mPE} / \mathrm{PA}$ nanocomposites, it was observed that the intensity of the absorption bands was increased due to the formation of the $\mathrm{OH}$ bond. ${ }^{34}$ Furthermore, the formation of additional bands at the peak of 1,645 and $1,539 \mathrm{~cm}^{-1}$ was attributed to the vibrations of $\mathrm{OH}$ group, which clearly indicate the interaction between the PVA, mPE, and PA. ${ }^{35}$ The interaction between PVA, mPE, and PA was also identified by a shifting of the $\mathrm{OH}$ group to a lower wave number from $3,325 \mathrm{~cm}^{-1}$ in pure PVA to $3,292 \mathrm{~cm}^{-1}$ in PVA/m PE/PA, confirming the addition of $\mathrm{mPE}$ and PA in the PVA matrix. ${ }^{34}$

\section{Porosity measurements}

The results of percentage porosity are shown in Figure 4. The pure PVA membrane exhibited a mean porosity of $76 \%$, whereas in the fabricated $\mathrm{PVA} / \mathrm{mPE} / \mathrm{PA}$, the porosity was found to be $87 \%$. The results clearly show that the PVA/ $\mathrm{mPE} / \mathrm{PA}$ membrane has high porosity $\sim 8.8 \%$ enhancement compared to pure PVA. Furthermore, the fabricated $\mathrm{PVA} / \mathrm{mPE} / \mathrm{PA}$ membrane showed a decrease in pore size diameter compared to control as indicated in Figure 5. The developed nanocomposite mesh exhibited a pore diameter of $340 \pm 86 \mathrm{~nm}$, while for the pure PVA, the pore size diameter was found to be $460 \pm 53 \mathrm{~nm}$. Sicchieri et al prepared PLGA-calcium phosphate (CaP) scaffolds for bone tissue engineering. It was reported that the scaffold with low pore

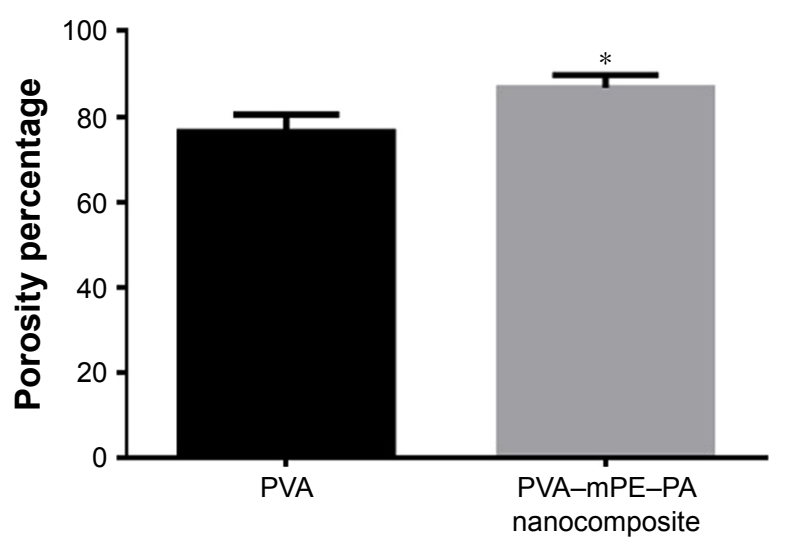

Figure 4 Porosity percentage of PVA membrane and PVA/mPE/PA nanocomposites.

Note: *Mean differences were significant compared with pure PVA $(P<0.05)$.

Abbreviations: mPE, metallocene polyethylene; PA, plectranthus amboinicus; PVA, polyvinyl alcohol. 
A

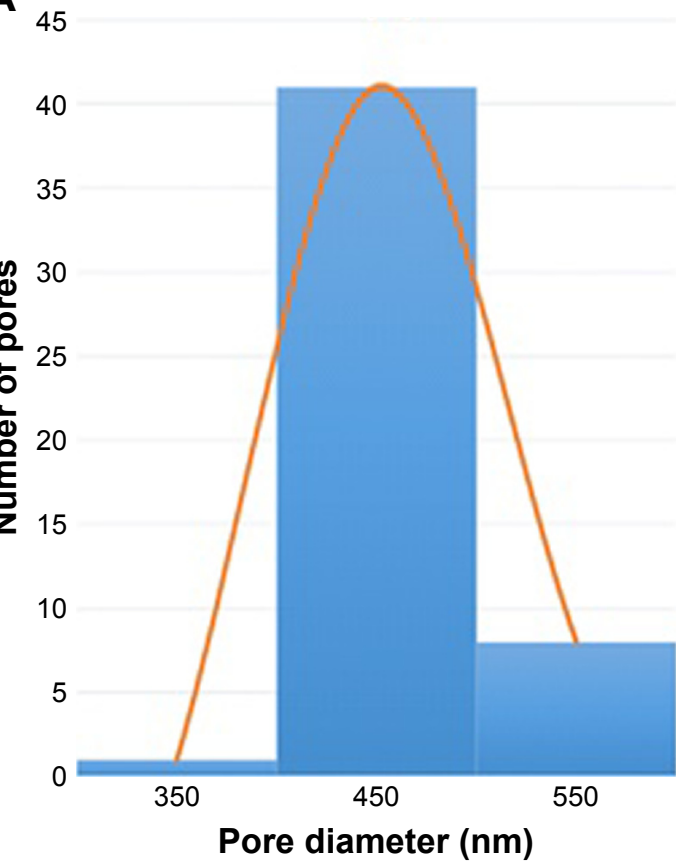

B

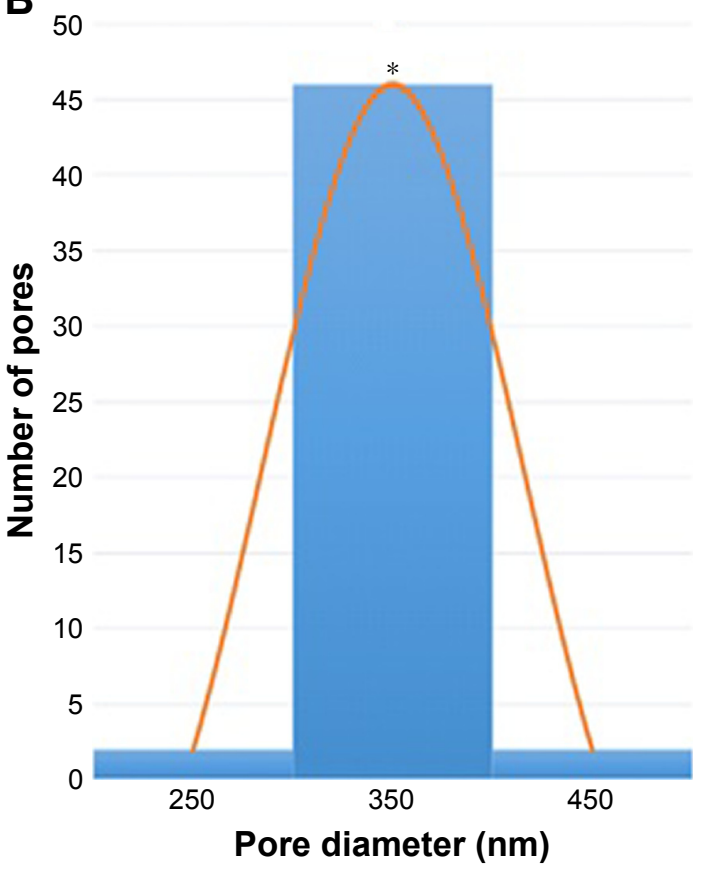

Figure 5 Pore size distribution of (A) PVA membrane and (B) PVA/mPE/PA nanocomposites.

Note: *Mean differences were significant compared with pure PVA $(P<0.05)$.

Abbreviations: mPE, metallocene polyethylene; PA, plectranthus amboinicus; PVA, polyvinyl alcohol.

size diameter showed enhanced osteoblast cell response and favored enhanced bone formation. ${ }^{36}$ Hence, the fabricated novel nanocomposites with decreased pore size diameter might be favorable for the new bone tissue formation.

\section{Wettability}

The wettability of electrospun PVA and PVA/mPE/PA is shown in Table 1. The contact angle measurements revealed that the contact angle of PVA/m PE/PA decreased compared to pure PVA. It was in agreement with our FTIR findings, which depicted the significant increase in $\mathrm{OH}$ intensity, confirming the hydrophilic nature of the nanocomposites. The contact angle of PVA was found to be $62^{\circ}$ whereas the contact angle of PVA/mPE/PA was found to be $51^{\circ}$, which clearly indicates that the addition of $\mathrm{mPE}$ and PA into the PVA matrix improved wettability of the fabricated hybrid membrane. Abdal-hay et al prepared electrospun nylon-6 scaffold

Table I Contact angle measurement of PVA and PVA/mPE/PA nanocomposites

\begin{tabular}{lll}
\hline $\begin{array}{l}\text { Serial } \\
\text { number }\end{array}$ & Sample & $\begin{array}{l}\text { Average contact } \\
\text { angle }\left(^{\circ}\right)\end{array}$ \\
\hline $\mathrm{I}$ & Pure PVA & $62 \pm 1.19$ \\
2 & PVA/mPE/PA nanocomposites & $51 \pm 1.32^{*}$ \\
\hline
\end{tabular}

Note: *Mean differences were significant compared with pure PVA $(P<0.05)$. Abbreviations: mPE, metallocene polyethylene; PA, plectranthus amboinicus; PVA, polyvinyl alcohol. blended with hydroxyapatite (HAp) for bone tissue formation. It was reported that the prepared nanocomposites showed hydrophilic nature and concluded that increased wettability is observed to be linked to enhanced bone regeneration. ${ }^{37}$

\section{TGA}

The TGA serves as a proof for chemical interactions and the formation of strong hydrogen bonds in the electrospun PVA and PVA/mPE/PA. The results of thermal analysis are shown in Figure 6. The results clearly showed that the pure PVA

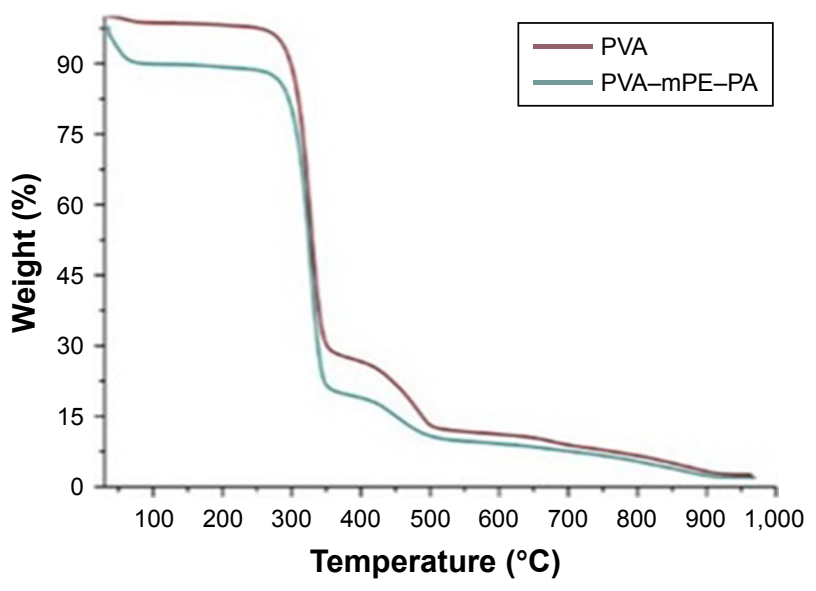

Figure 6 TGA of PVA membrane and PVA/mPE/PA nanocomposites.

Abbreviations: mPE, metallocene polyethylene; PA, plectranthus amboinicus; PVA, polyvinyl alcohol; TGA, thermogravimetric analysis. 

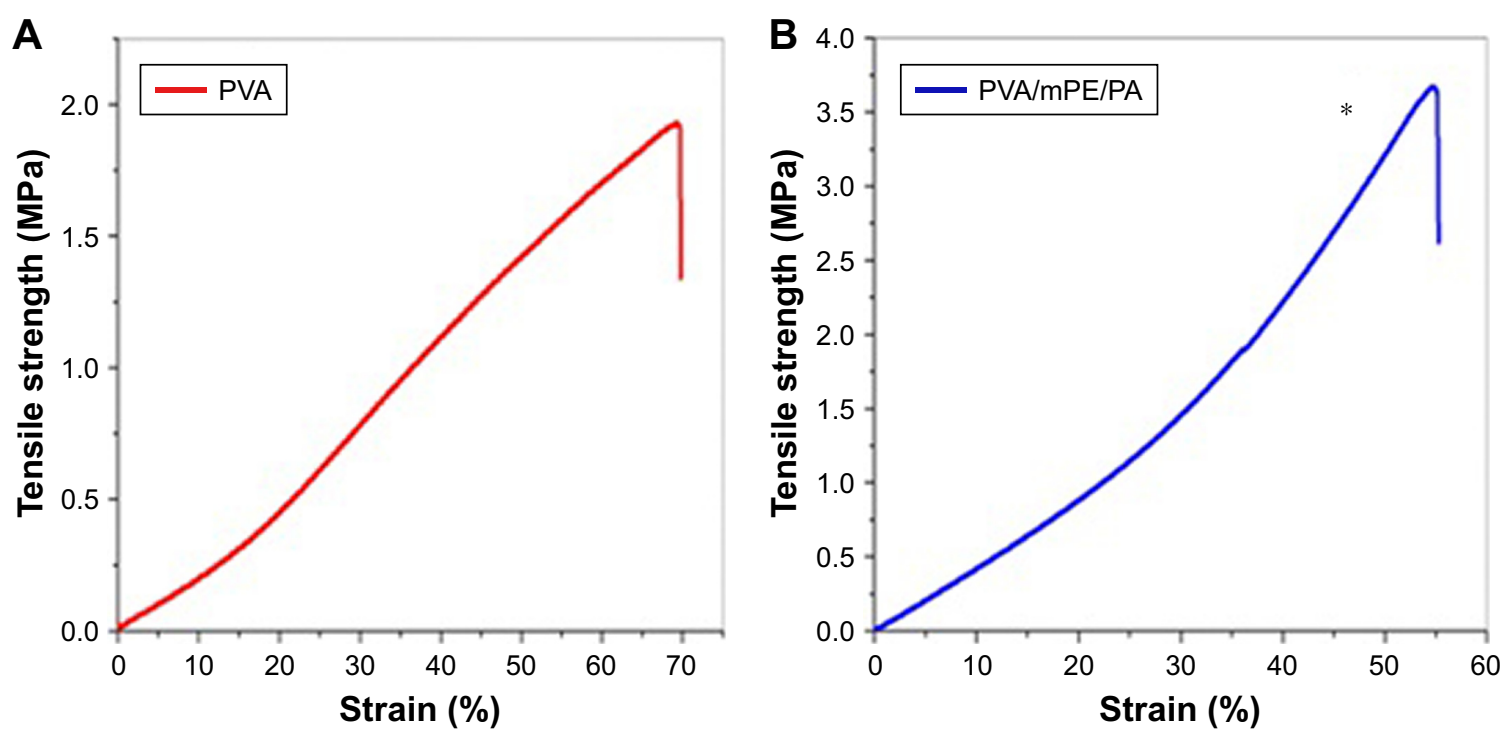

Figure 7 Mechanical testing of (A) PVA membrane and (B) PVA/mPE/PA nanocomposites.

Note: *Mean differences were significant compared with pure PVA $(P<0.05)$.

Abbreviations: $\mathrm{mPE}$, metallocene polyethylene; PA, plectranthus amboinicus; PVA, polyvinyl alcohol.

displayed two-stage degradation and the PVA/mPE/PA nanofibers depicted stages of degradation indicating lower thermal stability compared to control. The PVA/mPE/PA nanofibers showed initial onset temperature of $56^{\circ} \mathrm{C}$ whereas the onset temperature value for pure PVA was found to be $274^{\circ} \mathrm{C}$, which clearly indicates that the developed nanocomposites exhibited lower thermal stability. The reason for lower thermal stability was due to the presence of water molecules in the PVA matrix due to the addition of PA. Balaji et al fabricated polyurethane (PU) scaffold blended with honey and papaya fibers. It was observed that the addition of the papaya and honey into the PU matrix decreased the degradation of temperature, and our obtained results resemble the similar findings. ${ }^{38}$ Abdullah et al prepared a PVA scaffold blended with aloe vera using electrospinning technique. It was reported that the addition of aloe vera into the PVA matrix decreased the degradation temperature due to the high water content present in the aloe vera. ${ }^{35}$ Our developed hybrid nanocomposites showed decreased thermal stability, which might be due to the water molecules present in the fabricated nanocomposites.

\section{Mechanical properties}

The results of tensile strength and modulus for pure PVA and PVA/mPE/PA nanocomposites were shown in Figure 7. The electrospun PVA/mPE/PA nanocomposites exhibited higher tensile strength compared to the pure PVA nanofibers. The developed hybrid nanocomposites showed a tensile strength of $3.55 \pm 0.29 \mathrm{MPa}$, while for PVA, it was found to be $1.8 \pm 0.52 \mathrm{MPa}$. The mechanical testing results clearly revealed that the blending of the $\mathrm{mPE}$ into the PVA matrix has improved the tensile properties of the electrospun PVA nanofibers. Linh and Lee prepared a PVA scaffold blended with gelatin fibers for bone tissue engineering. It was reported that the tensile strength of pure PVA was $0.85 \pm 0.60 \mathrm{MPa}$ while a PVA-blended gelatin membrane exhibited a tensile strength of $\sim 4.20 \pm 0.40$ and concluded the fabricated PVA/gelatin membrane as a suitable candidate for bone tissue formation. ${ }^{30}$ In our developed nanocomposites, the tensile strength was found to be within the range of the above reported value and it might be used as a scaffold for the bone tissue formation.

\section{Functionalization}

The functionalization of PVA and PVA/mPE/PA nanocomposites was obtained using a heating method. The dissolution percentage of unfunctionalized PVA and $\mathrm{PVA} / \mathrm{mPE} / \mathrm{PA}$ nanocomposites after 1,7 , and 14 days is listed in Table 2. The SEM images of the functionalized PVA

Table 2 Dissolution percentage of unfunctionalized and functionalized PVA and PVA/mPE/PA nanocomposites

\begin{tabular}{llll}
\hline Days & $\begin{array}{l}\text { Unfunctionalized PVA } \\
\text { and PVA/mPE/PA } \\
\text { nanocomposites (\%) }\end{array}$ & $\begin{array}{l}\text { Functionalized } \\
\text { PVA (\%)* }\end{array}$ & $\begin{array}{l}\text { Functionalized } \\
\text { PVA/mPE/ } \\
\text { PA (\%)* }\end{array}$ \\
\hline 1 & 100 & 0 & 0 \\
7 & 100 & $0.39 \pm 0.07$ & $0.46 \pm 0.02$ \\
14 & 100 & $1.26 \pm 0.30$ & $1.65 \pm 0.57$ \\
\hline
\end{tabular}

Note: *Mean differences were significant compared with unfunctionalized PVA and PVA/mPE/PA nanocomposites $(P<0.05)$.

Abbreviations: $\mathrm{mPE}$, metallocene polyethylene; PA, plectranthus amboinicus; PVA, polyvinyl alcohol. 


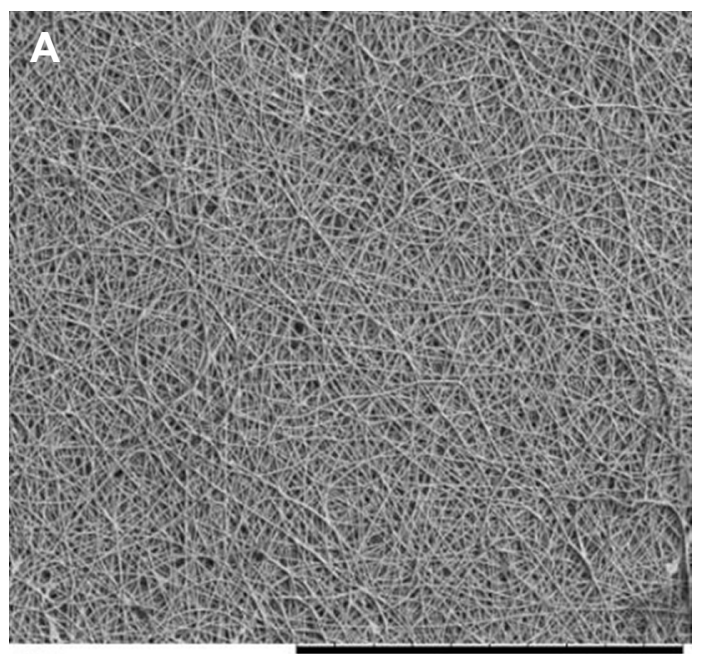

SEM

$\times 1.0 \mathrm{k} 100 \mu \mathrm{m}$ SEM

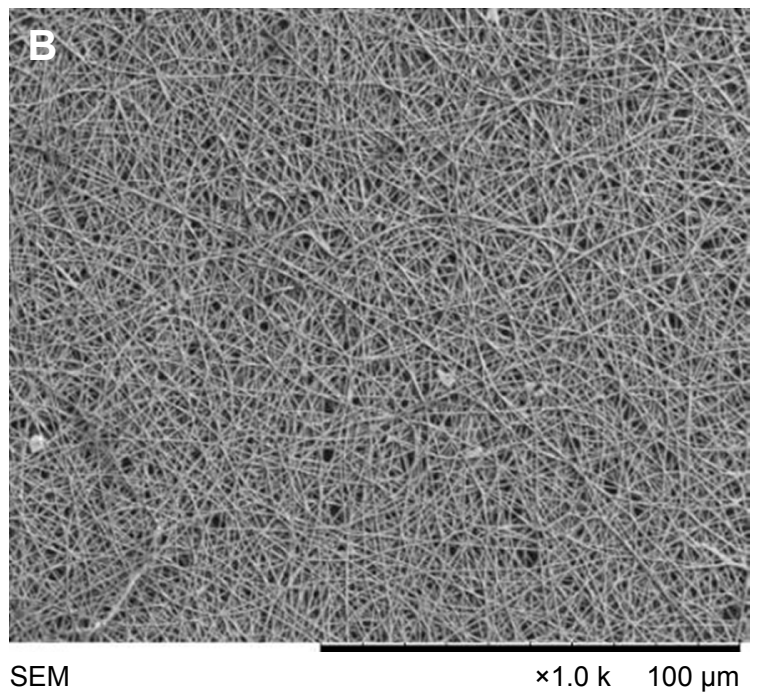

Figure 8 SEM images of functionalized (A) PVA membrane and (B) PVA/mPE/PA nanocomposites after I day.

Abbreviations: mPE, metallocene polyethylene; PA, plectranthus amboinicus; PVA, polyvinyl alcohol; SEM, scanning electron microscopy.

and PVA/mPE/PA nanocomposites after 1, 7, and 14 days are shown in Figures 8A and B, 9A and B, and 10A and B, respectively. The heat treatment improved the degradation behavior of the PVA membrane. It was reported that the heat treatment causes an increase in entanglements of longer polymer chains, which results in an increase in molecular weight. Furthermore, an increase in molecular weight reduces the formation of crystals, which favored the decreased weight loss. ${ }^{39}$ In our study, heat treatment might reduce the formation of crystals in PVA nanofibers, which ultimately reduces the weight loss in water. Asran et al prepared a nanofibrous scaffold based on PVA blended with collagen and HAp for bone tissue engineering. It was reported that the addition of HAp into the PVA matrix reduced the crystal structure of the PVA, which favored the reduction in weight losss. ${ }^{32}$ Hence, in our study, the addition of MPE and PA might also be the reason for decreasing the size of the crystal structure of the PVA, which resulted in a reduced weight loss. Similarly, in a recent study, Hong prepared a PVA scaffold blended with $\mathrm{AgNO}_{3}$ nanoparticles and performed heat treatment under ultra violet (UV) lamp. It was reported that the heat treatment of electrospun $\mathrm{PVA} / \mathrm{AgNO}_{3}$ made them insoluble in a moist environment. ${ }^{40}$ Hence, functionalizing the PVA using heat renders the nanocomposite insoluble in an aqueous environment. The functionalized PVA was explored for its blood compatibility in order to assess its safety.

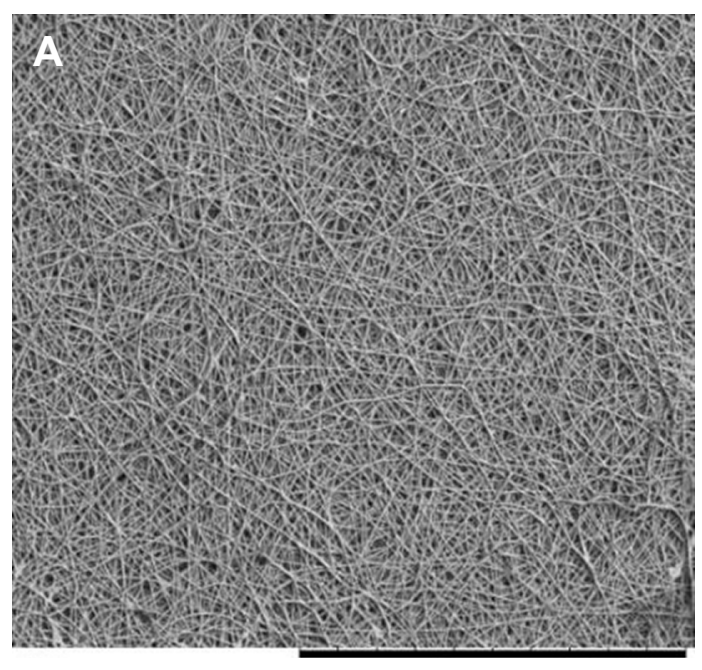

SEM

F $\quad \times 1.0 \mathrm{k} 100 \mu \mathrm{m}$ SEM

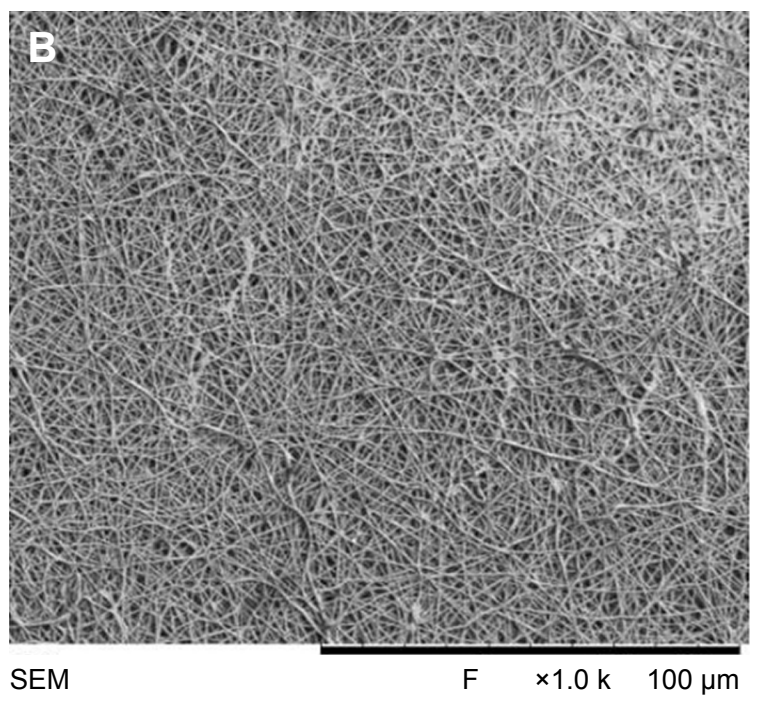

Figure 9 SEM images of functionalized (A) PVA membrane and (B) PVA/mPE/PA nanocomposites after 7 days.

Abbreviations: $\mathrm{mPE}$, metallocene polyethylene; PA, plectranthus amboinicus; PVA, polyvinyl alcohol; SEM, scanning electron microscopy. 

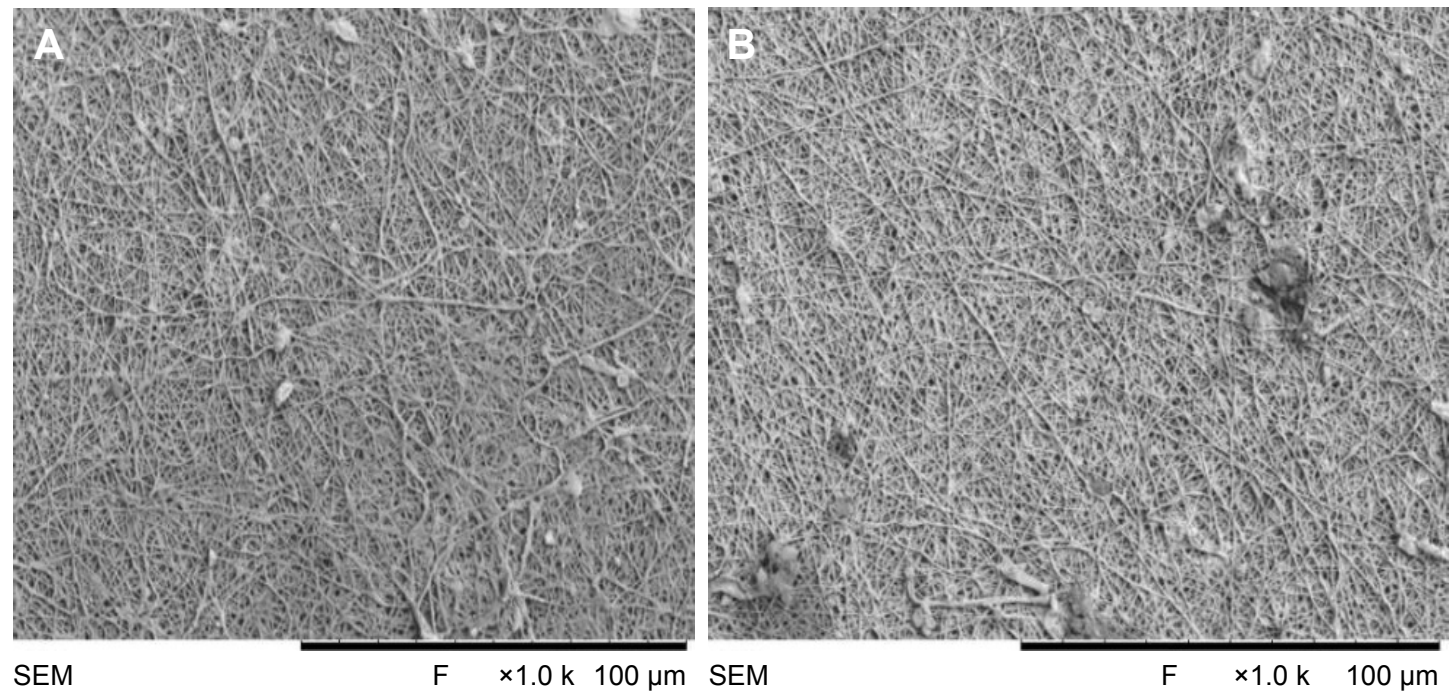

Figure 10 SEM images of functionalized (A) PVA membrane and (B) PVA/mPE/PA nanocomposites after 14 days.

Abbreviations: mPE, metallocene polyethylene; PA, plectranthus amboinicus; PVA, polyvinyl alcohol; SEM, scanning electron microscopy.

\section{Coagulation assay measurements}

The blood compatibility assessments play a significant role in deciding the application of developed implants in biomedical applications. When the implants contact with the blood, they absorb more plasma proteins and also enhance platelet surface interaction, which causes the thrombus formation, which ultimately results in the failure of the implants. Hence, it is required to design an implant, which should minimize the plasma protein adsorption and increase the thromboresistance..$^{41}$ The formation of thrombus was initiated by a blood coagulation cascade, which follows two pathways, namely the intrinsic and extrinsic pathways. In the intrinsic pathway, the coagulation of blood was activated by plasma factors whereas, in the extrinsic pathway, the blood coagulation was activated by tissue factors. ${ }^{42}$ The APTT assay determines the blood compatibility through the intrinsic pathway while the PT determines blood compatibility through the extrinsic pathway. The results of the APPT and PT assays are shown in Figure 11. It was observed that the PVA/mPE/PA matrix showed delayed blood clotting time compared with pure PVA. For the APTT assay, the blood clotting time of $\mathrm{PVA} / \mathrm{mPE} / \mathrm{PA}$ was found to be $177 \pm 3.05 \mathrm{~s}$ whereas, for pure PVA, the blood clotting was found to be $147 \pm 3.6 \mathrm{~s}$. Similarly, for the PT assay, the blood clotting time of PVA $/ \mathrm{mPE} / \mathrm{PA}$ was found to be $75 \pm 2.0 \mathrm{~s}$ whereas, for pure PVA, the blood clotting time was observed to be $61 \pm 2.0 \mathrm{~s}$. Hence, the addition of $\mathrm{mPE}$ and PA into the PVA matrix improved the anticoagulant and thrombogenic nature of pure PVA. Furthermore, hemolysis was performed to investigate the safety of RBCs on the electrospun PVA/mPE/PA nanocomposites.
The results of the hemolysis assay are shown in Figure 12. From results obtained, the hemolytic index of pure PVA was $1.6 \%$ while, for electrospun PVA $/ \mathrm{mPE} / \mathrm{PA}$ nanocomposites, the index was only $0.6 \%$. It was reported, if the hemolysis percentage was $>2 \%$, the material was considered as hemolytic material, and when the percentage was $<2 \%$, then the material was considered as nonhemolytic material. ${ }^{43}$ Hence our fabricated nanocomposites showed only $0.6 \%$, which was $<1 \%$ indicating nonhemolytic material. A recent report suggested that the blood compatibility is influenced by a combination of factors such as surface roughness, surface energy and surface tension, surface wettability, and fiber

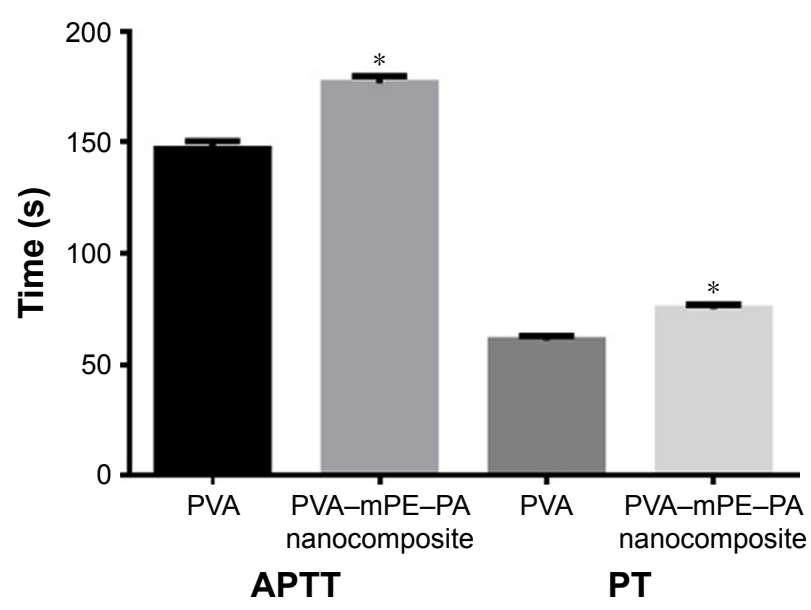

Figure II APTT and PT assays of PVA membrane and PVA/mPE/PA nanocomposites.

Note: *Mean differences were significant compared with pure PVA $(P<0.05)$. Abbreviations: APTT, activated partial thromboplastin time; mPE, metallocene polyethylene; PA, plectranthus amboinicus; PT, prothrombin time; PVA, polyvinyl alcohol. 


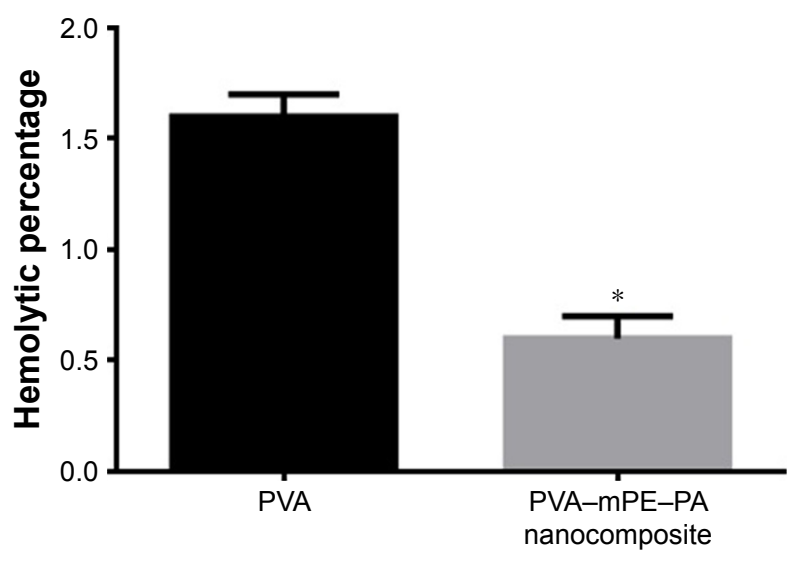

Figure 12 Hemolysis assay of PVA membrane and PVA/mPE/PA nanocomposites. Note: *Mean differences were significant compared with pure PVA $(P<0.05)$. Abbreviations: mPE, metallocene polyethylene; PA, plectranthus amboinicus; PVA, polyvinyl alcohol.

diameters. ${ }^{44}$ Hence, the prediction of the combinational factors affecting the blood compatibility of the developed nanocomposites is cumbersome. Vincent et al developed multiple scaffolds based on degarapol and PLGA and investigated the significance of blood compatibility on different fiber diameters. It was reported that a small fiber diameter has a great influence in improving the blood compatibility of the fabricated nanocomposites. ${ }^{45}$ Manikandan et al prepared a PU scaffold blended with murivenenai oil for tissue engineering applications. It was observed that the fabricated nanocomposites exhibited a hydrophilic nature indicating improved surface wettability. Furthermore, the PU-blended with murivennai oil nanocomposite showed improved blood compatibility compared with pure PU. ${ }^{46}$ In our study, the fabricated PVA/mPE/PA nanofibers exhibited smaller fiber diameter and improved surface wettability compared with the pure PVA fibers, which might be attributed to the enhanced blood compatibility.

\section{Conclusion}

In this study, we successfully fabricated a hybrid nanocomposite membrane based on PVA, mPE, and PA fibers. The hybrid nanocomposites exhibited reduced fiber diameter in the nanometer range and also a hydrophilic nature, as revealed in contact angle measurements. The mechanical results revealed that the hybrid membrane showed enough tensile strength required for bone tissue engineering. A hybrid nanocomposite comprising mPE, PVA and PA delayed blood clotting and displayed a low hemolytic index, indicating better blood compatibility. Hence, the newly developed nanocomposites mimicking the ECM structure might be a suitable scaffold for repairing bone defects.

\section{Acknowledgment}

This study was supported by the Ministry of Higher Education Malaysia with grant no Q.J130000.2545.14H59.

\section{Disclosure}

The authors report no conflicts of interest in this work.

\section{References}

1. Ong KL. New biomaterials for orthopedic implants. Int J Nanomed. 2015;7:107-130

2. Zhao L, Zhao J-L, Wan L, Wang S-K. The study of the feasibility of segmental bone defect repair with tissue-engineered bone membrane: a qualitative observation. Strategies Trauma Limb Reconstr. 2008;3(2):57-64.

3. Amini AR, Laurencin CT, Nukavarapu SP. Bone tissue engineering: recent advances and challenges. Crit Rev Biomed Eng. 2012;40(5): 363-408.

4. Polo-Corrales L, Latorre-Esteves M, Ramirez-Vick JE. Scaffold design for bone regeneration. J Nanosci Nanotechnol. 2014;14(1):15-56.

5. O'brien FJ. Biomaterials \& scaffolds for tissue engineering. Mater Today. 2011;14(3):88-95.

6. Dhandayuthapani B, Yoshida Y, Maekawa T, Kumar DS. Polymeric scaffolds in tissue engineering application: a review. Int J Polym Sci. 2011; 2011:19.

7. Sheikh Z, Najeeb S, Khurshid Z, Verma V, Rashid H, Glogauer M. Biodegradable materials for bone repair and tissue engineering applications. Materials. 2015;8(9):5744-5794.

8. Zohora FT, Azim AYMA. Biomaterials as a porous scaffold for tissue engineering applications: a review. Eur Sci J. 2014;10:186-209.

9. Kar KK, Rana S, Pandey J. Handbook of Polymer Nanocomposites Processing; Performance and Application. Berlin, Heidelberg: Springer Verlag; 2015.

10. Wang J, Wang L, Zhou Z, et al. Biodegradable polymer membranes applied in guided bone/tissue regeneration: a review. Polymer. 2016; $8(4): 115$

11. Wang X, Ding B, Li B. Biomimetic electrospun nanofibrous structures for tissue engineering. Mater Today. 2013;16(6):229-241.

12. Cheung HY, Lau KT, Lu TP, Hui D. A critical review on polymerbased bio-engineered materials for scaffold development. Comp B Eng. 2007;38(3):291-300.

13. Heydarkhan-Hagvall S, Schenke-Layland K, Dhanasopon AP, et al. Three-dimensional electrospun ECM-based hybrid scaffolds for cardiovascular tissue engineering. Biomaterials. 2008;29(19):2907-2914.

14. Liu W, Thomopoulos S, Xia Y. Electrospun nanofibers for regenerative medicine. Adv Healthcare Mater. 2012;1(1):10-25.

15. Vasita R, Katti DS. Nanofibers and their applications in tissue engineering. Int J Nanomed. 2006;1(1):15.

16. Liu H, Ding X, Zhou G, Li P, Wei X, Fan Y. Electrospinning of nanofibers for tissue engineering applications. J Nanomater. 2013;3:11.

17. Katti DS, Robinson KW, Ko FK. Bioresorbable nanofiber-based systems for wound healing and drug delivery: optimization of fabrication parameters. J Biomed Mater Res B Appl Biomater. 2004;70(2):286-296.

18. Reneker DH, Yarin AL, Fong H, Koombhongse S. Bending instability of electrically charged liquid jets of polymer solutions in electrospinning. J Appl Phys. 2000;87:4531-4547.

19. Yarin AL, Koombhongse S, Reneker DH. Taylor cone and jetting from liquid droplets in electrospinning of nanofibers. J Appl Phys. 2001; 90:4836-4846.

20. Gaaz TS, Sulong AB, Akhtar MN, Kadhum AA, Mohamad AB, Al-Amiery AA. Properties and applications of polyvinyl alcohol; halloysite nanotubes and their nanocomposites. Molecules. 2015; 20(12):22833-22847.

21. Baker MI, Walsh SP, Schwartz Z, Boyan BD. A review of polyvinyl alcohol and its uses in cartilage and orthopedic applications. J Biomed Mater Res B Appl Biomater. 2012;100(5):1451-1457. 
22. Sunny MC, George KE. Studies on Metallocene Polyolefin and Polyvinyl Chloride for Blood and Blood Component Storage Applications [Doctoral dissertation]. Cochin University of Science \& Technology, Ernakulam; 2006.

23. Vellayappan MV, Jaganathan SK, Muhamad II. Unravelling the potential of nitric acid as a surface modifier for improving the hemocompatibility of metallocene polyethylene for blood contacting devices. Peer J. 2016;4:e1388.

24. Narayanan KB, Sakthivel N. Phytosynthesis of gold nanoparticles using leaf extract of Coleus amboinicus Lour. Mater Charact. 2010; 61(11):1232-1238.

25. Kaliappan ND, Viswanathan PK. Pharmacognostical studies on the leaves of Plectranthus amboinicus (Lour) Spreng. Int Green Pharm. 2008;2(3):182-184.

26. Arumugam G, Swamy MK, Sinniah UR. Plectranthus amboinicus (Lour.) Spreng: botanical; phytochemical; pharmacological and nutritional significance. Molecules. 2016;21(4):369.

27. Turaga U, Singh V, Gibson A, et al. Functionalized antimicrobial electrospun poly (vinyl alcohol) nanowebs. J Eng Fabr Fiber. 2016;11(2):60-67.

28. Zhang YZ, Venugopal J, Huang ZM, Lim CT, Ramakrishna S. Crosslinking of the electrospun gelatin nanofibers. Polymer. 2006;47(8): 2911-2917.

29. Ayyar M, Mani MP, Jaganathan SK, Rathanasamy R. Preparation; characterization and blood compatibility assessment of a novel electrospun nanocomposite comprising polyurethane and ayurvedic-indhulekha oil for tissue engineering applications. Biomed Eng. Epub 2017 Jul 5.

30. Linh NT, Lee BT. Electrospinning of polyvinyl alcohol/gelatin nanofiber composites and cross-linking for bone tissue engineering application. J Biomater Appl. 2012;27(3):255-266.

31. Ren G, Xu X, Liu Q, et al. Electrospun poly (vinyl alcohol)/glucose oxidase biocomposite membranes for biosensor applications. React Funct Polym. 2006;66(12):1559-1564.

32. Asran AS, Henning S, Michler GH. Polyvinyl alcohol-collagenhydroxyapatite biocomposite nanofibrous scaffold: mimicking the key features of natural bone at the nanoscale level. Polymer. 2010;51(4): 868-876.

33. Mohandas H, Sivakumar G, Kasi P, Jaganathan SK, Supriyanto E. Microwave-assisted surface modification of metallocene polyethylene for improving blood compatibility. Biomed Res Int. 2013;2013:253473.
34. Tarun K, Gobi N. Calcium alginate/PVA blended nano fiber matrix for wound dressing. Ind J Fiber Text Res. 2012;3:127-132.

35. Abdullah NA, Sekak KA, Ahmad MR, Effendi TB. Characteristics of electrospun PVA-aloe vera nanofibers produced via electrospinning. Proceedings of the International Colloquium in Textile Engineering. Fashion Apparel Design. 2014:7-11.

36. Sicchieri LG, Crippa GE, de Oliveira PT, Beloti MM, Rosa AL. Pore size regulates cell and tissue interactions with PLGA-CaP scaffolds used for bone engineering. J Tissue Eng Regen Med. 2012;6(2):155-162.

37. Abdal-hay A, Pant HR, Lim JK. Super-hydrophilic electrospun nylon-6/ hydroxyapatite membrane for bone tissue engineering. Eur Polym $J$. 2013;49(6):1314-1321.

38. Balaji A, Jaganathan SK, Ismail AF, Rajasekar R. Fabrication and hemocompatibility assessment of novel polyurethane-based bio-nanofibrous dressing loaded with honey and carica papaya extract for the management of burn injuries. Int J Nanomedicine. 2016;11:4339-4355.

39. Mohsen M, Saifullah AN, Cay A. Physical stabilisation of electrospun poly(vinyl alcohol) nanofibres: comparative study on methanol and heat-based crosslinking. J Mater Sci. 2015;50:1943-1957.

40. Hong KH. Preparation and properties of electrospun poly (vinyl alcohol)/ silver fiber web as wound dressings. Polym Eng Sci. 2007;47(1): 43-49.

41. Dhandayuthapani B, Varghese SH, Aswathy RG, Yoshida Y, Maekawa T, Kumar DS. Evaluation of antithrombogenicity and hydrophilicity on zein-SWCNT electrospun fibrous nanocomposite scaffolds. Int $J$ Biomater. 2012;345029:1-10.

42. Davie EW, Fujikawa K. Basic mechanisms in blood coagulation. Annu Rev Biochem. 1975;44:799-829.

43. Fazley M, Elahi GG, Lu W. Hemocompatibility of surface modified silk fibroin materials; a review. Rev Adv Mater Sci. 2014;3:148-159.

44. Huang N, Yang P, Leng YX, et al. Hemocompatibility of titanium oxide films. Biomaterials. 2003;24:2177-2187.

45. Vincent M, Thomas H, Heike H, Viola V, Daniel E. Influence of fiber diameter and surface roughness of electrospun vasculargrafts on blood activation. Acta Biomater. 2012;8(12):4349-4356.

46. Manikandan A, Mani MP, Jaganathan SK, Rajasekar R, Jagannath M. Formation of functional nanofibrous electrospun polyurethane and murivenna oil with improved haemocompatibility for wound healing. Polym Test. 2017;61:106-113.
International Journal of Nanomedicine

\section{Publish your work in this journal}

The International Journal of Nanomedicine is an international, peerreviewed journal focusing on the application of nanotechnology in diagnostics, therapeutics, and drug delivery systems throughout the biomedical field. This journal is indexed on PubMed Central, MedLine, CAS, SciSearch ${ }^{\circledR}$, Current Contents ${ }^{\circledR} /$ Clinical Medicine,

\section{Dovepress}

Journal Citation Reports/Science Edition, EMBase, Scopus and the Elsevier Bibliographic databases. The manuscript management system is completely online and includes a very quick and fair peer-review system, which is all easy to use. Visit http://www.dovepress.com/ testimonials.php to read real quotes from published authors. 